\title{
The Analysis and Countermeasures toward the Inbound Tourist Market of the Silk Road on Land
}

\author{
Huize Chen \\ Economy Management Department of Xian Aviation University, West Second Ring Road 259, Xi'an \\ 710077, China. \\ 5298916@qq.com
}

Keywords: Silk Road, inbound tourist market, countermeasures.

\begin{abstract}
The development of tourism in a district is affected by many factors. This paper analyzes the inbound tourist market of the Silk Road on land and points out the difficulties of the development of inbound tourist market this area are facing. At last, the paper puts forward some countermeasures from the perspectives of stakeholders related to tourist industry in this area.
\end{abstract}

\section{Introduction}

The development of regional tourism economy is not just related to one department or two. In 2014, China put forward the development strategy $\neg$----Action Plan on the China-proposed Belt and Road Initiative. It creates an excellent opportunity for development along the Silk Road. The inbound tourism in this area is facing opportunities and challenges as well. In order to better expand the inbound tourism market in this region, related stakeholders should play an active role.

\section{The analysis on present inbound tourist market of the Silk Road}

In this paper, the Silk Road involves provinces and autonomous regions like Shaanxi, Ningxia, Gansu, Qinghai, and Xinjiang. After the strategy of Constructing the Silk Road Economy Belt was put forward, the Silk Road once again becomes the focus of attention of people and the world. In order to show the world the charm of the Silk Road and let more people know about the Silk Road, to develop the inbound tourism of the region is the best choice.

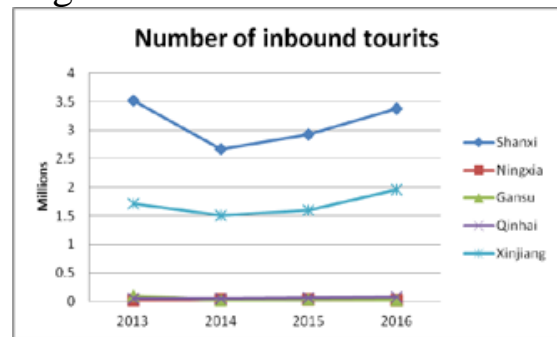

Fig. 1 The curve diagram of inbound tourist number in provinces and district along the Silk Road

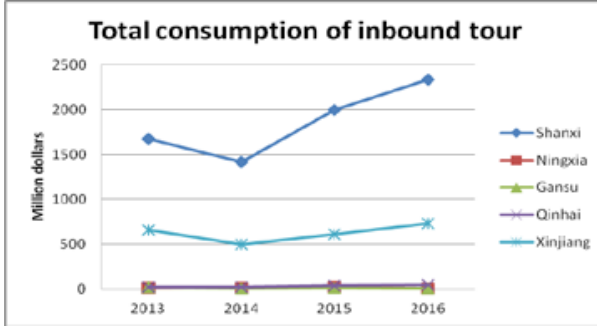

Fig. 2 The curve diagram of total consumption of inbound tour in provinces and district along the Silk Road

Through the analysis of chart 1 and chart 2, we can see that the inbound tourist market in the provinces and autonomous regions alone the Silk Road develops unevenly. More than 96\% inbound tourists traveling to this area visited Shaanxi and Xinjiang. The per capita consumption of inbound 
tourists has been in steady decline during the past few years. But the number of inbound tourists has been rising except 2014. The total area of the Silk Road Economic Belt is about 3.11 million square kilometers, accounting for $32.4 \%$ of the total area of China. But the total number of foreign travelers visiting this area accounts for about $4 \%$ of the inbound tourists to China.

\section{Challenges of inbound tourist market development of the Silk Road Economic Belt}

\subsection{The downturn of inbound tourism market}

According to statistics from 2012 to 2014, China's inbound tourist arrivals fell by $2.23 \%, 2.51 \%$ and $0.45 \%$ respectively. However, according to the statistics of the World Tourism Organization, the number of international tourists is increasing year by year. The comparison of declining and increasing indicates that China's inbound tourism is facing severe challenges. It is the result of internal and external causes such as the downturn of the world economy, the rising of RMB exchange rate, the lacking of attractive tourist products, air pollution and so on.

\subsection{Lacking attractive theme tourist products}

Although the Silk Road has been listed as one of the World Heritages and it has become one of the popular tourist destination in the world, attractive theme tourist products are still lacking. Recently, many distinctive tourist products have been launched by provinces and regions along the Silk Road such as "the highlight tour of Xi'an", "the Perfect Tour along the West Bank", "the Highlight Tour along the Silk Road”, "the Special Train Tour along the Silk Road” and so on. Most of the products still belong to sightseeing products, so they are not competitive in the world tourist market.

\subsection{Far away from the international tourist source market}

The provinces and autonomous regions along the Silk Road are far away from the major international inbound tourist markets such as Europe, America, Japan, Korea and so on. Taking Los Angeles as an example, the transportation to tour the Silk Road in China and return will at least take a tourist eighty hours. The boring journey will make the tourists uninterested in the tour along the Silk Road. On the other hand, the cost of transportation for the tourists will exceed 4000 US dollars excluding the accommodation, meals, admission fees and so on. It will make them rethink their decisions.

\subsection{To be improved reception service}

Due to the constraints of economic development conditions, the hardware and software levels of inbound tourists reception service along the Silk Road are to be improved. Although the hardware, such as the tourism infrastructure is constantly improved, health and safety conditions have made great progress, the software such as the quality of personnel and service level still can not meet the needs of the inbound tourism market. For example, in some scenic spots and even 5A attractions, many staff don't master any foreign language. They are even unable to answer foreign tourists' consulting. In addition, some of the practitioners have resigned because of the depression of inbound tourism. These will affect the overall level of the inbound tourist reception services.

\section{The definition of inbound tourism market stakeholders of the Silk Road}

From the perspective of stakeholders' influence on enterprises, Frederick (1988) divided stakeholders into direct stakeholders and indirect stakeholders. The direct stakeholders are directly related to the market transactions while indirect stakeholders are indirectly related to them. The development of regional tourism is inseparable from the participation of stakeholders. Therefore, it is meaningless to put aside stakeholders to study regional tourism development. According to the relationship between inbound tourism market, stakeholders of the inbound tourism market of the Silk Road are divided as follows: first, the direct stakeholders, including: governments, inbound tourists, tourism investors, tourism enterprises, tourism practitioners, traffic units, local residents etc; second, 
indirect stakeholders, including industry associations, finance sectors, trade sectors, media sectors, education departments, medical departments etc.

\section{The stakeholders' responsibilities of developing the inbound tourist market of the Silk Road}

\subsection{The local governments}

In the process of regional tourism development, the government should make clear its position. Although China carries out the strategy of government conducted tourism development, the governments can not directly intervene the inbound tourism operation. What the governments should do are as follows:

\subsubsection{Well planning}

Local governments should combine the domestic and international tourism to plan the development of local tourism. Specifically, the main contents include: the layout of the tourism industry, investment and development of tourism education, infrastructure construction, the protection of ecological environment, etc. The layout of local tourism industry should not only reflect the local characteristics and highlight but also should meet the national Belt and Road Initiative strategy. At the same time, it is necessary to formulate policies to promote the development of local tourism such as increasing investment, improve the environment, enhance the image as a tourist destination and so on.

\subsubsection{Supervising the tourism market}

As the development of tourism market is benefit oriented. In this process, the government's supervision should not be missing, otherwise the tourism market will be in a state of disorderly competition. Economic and legal means should be applied.

\subsubsection{Bettering related public services.}

Local governments along the Silk Road should create opportunities to develop inbound tourism such as facilitating the annual verification of inbound tourist enterprises, facilitating the procedure of inbound tour, strengthening the protection of the benefits of foreign tourists and so on.

\subsubsection{Good coordinating.}

The local governments along the Silk Road should coordinate the development of different departments including tourism industry, the relationship between tourism enterprises and tourism related departments, enterprises and other industries to improve the overall tourism image of the Silk Road. It is suggested that a special committee should be founded by the local governments along the Silk Road of provincial level which is responsible for the overall planning, publicizing of tourism of Silk Road. At the same time, tourism operation platform of the Silk Road based on the Internet should be built, which could realize the operation of B to B, B to C, O to O and other functions. After these, the Silk Road inbound tourism will be improved and strengthened.

\subsection{Tourism enterprisers}

\section{(1)Travel services}

With the growing up of inbound tourism, more and more foreign travelers will choose to travel by themselves. The trend will definitely affect the business of the travel services along the Silk Road. They should better their service and provide finely planned and distinctive products, at the mean time, they should strengthen the cooperation between the tour companies in main tourist source countries. It would be a great innovation if the jointly establish an international B to B tour business platform.

(2)Scenic spots

Scenic spots along the Silk Road should optimize the combination of natural environment, landscaping and culture to highlight the uniqueness of the tourist products. Scenic spots should improve their service level including the staff's skill of speaking at least one foreign language. The administration of the scenic spots also can set up the web site of the scenic spots in different foreign languages.

(3) Hotels 
Hotels may be the most highly internationalized tourism reception department, because of its scheduled reception procedures, relatively fixed service content. In the reception of foreign tourists, Hotels along the Silk Road should study the needs of foreign tourists, provide targeted, personalized service. Also it is advised to take the advantage of the Internet and other communication means to facilitate customer's consulting, booking and other requirements. They also can take advantage of the website to strengthen the external publicity and marketing..

(4) Shops

The sales of tourist commodities can not only promote the development of local economy, but also left tourists with good memories. However, there are some unique phenomena in China's tourism. Tour groups received by travel agencies only can go shopping in shops designated by the governments. This is clearly against the market discipline. The matter of the market should be resolved by the market itself. The shopping traps have greatly influenced the image of China tour including that of the Silk Road. The tourist shopping market also should be regulated.

\subsection{Employees}

During the process of receiving inbound tourists, the service provided ye the employees not only represents the overall image of the Silk Road, but also the image of china. Therefore, the employees in tourism should be well trained. In addition, the rights of employees should also be protected. For example, many tour guides are not salaried by the travel agencies. Their income is mainly from the commissions of tourists' shopping and additionally visited scenic spots. So what they focus on is not service itself but the commissions. It's not the problem of the quality of the tour guides but the lack of the laws and regulations.

\subsection{Local residents}

The attitude of residents toward tourists will certainly impact the development of local tourism market. At the same time, if the development of tourism industry destroy the local ecological environment, squeeze the local residents living space, it is bound to cause local residents antipathy to the tourists. This conflict should be avoided. A large number of ethnic minorities distribute along the Silk Road. In the process of developing inbound tourism, it is necessary to carry out education for local residents, to improve their understanding of the tourism development and to create conditions for their employment. The conflict between tourism development and traditional ethnic culture should also be avoided.

\section{Conclusion}

In a word, an inter-government cooperative organization should be founded. Because the tourism in China is government oriented, all the regional tour cooperations should be carried out by the organization. To expand the inbound tourist market, all relevant departments and individuals should take their responsibility actively.

\section{References}

[1]Zhou Wuzhong, Huang Dang. On the relationship between the development of tourism industry and government. Famous Cities in China.2010.10.

[2]Gao Li. Research on regional tourism development based on Stakeholder Theory. Graduation thesis form Nankai University.2011.05.

[3]Yang Zhiyong, Siqin. Analysis and forecast of Chinese Inbound Tourism Market. Future and Development.2010.10.

[4]Daibin. A new approach to the development of inbound tourism from a global perspective. http://www.ctaweb.org/html.. 
[5]Ding Xuhui, Tianze. Economic growth of inbound tourism in the Silk Road Economic Zone. Journal of Southwest Minzu University.2009.09.

[6]Ma Yaofeng, Liang Xuefeng. Study on the tourism cooperation of the transnational Silk Road. Tourism Economy.2006.02. 